\title{
Bare Lives in Invisible Cities: The Example of a Setting of a Stopover
}

\author{
ElinaTriantafyllidou", Fani Vavili \\ Faculty of Technology, School of Architecture, Aristotle University of Thessaloniki, Greece
}

Copyright $\bigcirc 2017$ by authors, all rights reserved. Authors agree that this article remains permanently open access under the terms of the Creative Commons Attribution License 4.0 International License

\begin{abstract}
This paper deals with, what we call, "Bare lives in invisible cities". Bare lives are defined as the subjects while invisible cities are the spaces in which they move, live temporarily or for a long time. Who are those who have no permanent home and end up changing settings, not because they choose to, but because of prevailing conditions at their place of origin? The stage has been set, the roles have been given and the dis-placed people become the central characters of the drama being unfolded lately in South-East Europe. The specific groups of people being referred here are refugees or immigrants, requiring asylum and presented as 'bare lives,' that forcibly left their grounds, due to political, economic and geographic reasons. This research, having defined its subjects, attempts to set them in the invisible cities' grounds. What is the definition of an invisible city? Where is it located? What kind of new spatial relations are formed; are some questions that require answering. Presenting an alternative architectural solution in 'extreme conditions', this paper aims to start a discussion about a new type of co-habitation in the city.
\end{abstract}

Keywords Refugees, Asylum Seekers, Re-use Architecture, Container, Social Support

\section{Introduction}

These "redundancies,"[1] herein introduced as 'bare lives,' like other figures of Giacometti embarked on "ship of fools"[2] and disembarked in an "Invisible city."[3]

Nowadays, many are those who abandon their grounds to seek new ones. Refugees and migrants from countries like Syria, Afghanistan and other war-tom lands are forced to leave their homes and abandon everything behind as they face the indiscriminate violence of armed conflict which imposes serious risks of torture, inhuman or degrading treatment. [4] They pursue a better life, by trying to end up in Western or Northern Europe aiming to be reunited with family, receive greater protection, and have greater opportunities to make a living. [5] Through painful procedures [6] they cross borders between cultures and identities, recomposing or rebuilding spaces at an urban ground.

In these conditions, in our cities a new, invisible city [7] appears, which locals can see, perceive but simply pass by. The city begins to be inhabited by forms of multicultural cohabitation, not only in its centre, but also, beyond its limits giving a new dynamic to the city. [8] The common concept of a community is transformed, as it does not represent a neighbourhood or ethnic group. [9]

It is a fact that the recent increase of refugees or immigrants in our cities already causes conflicts and the signs of an imminent eruption emerge, causing us to react. So lets' reflect or, on the other side, let's bring back the 'ships of fools' as were presented by Michael Foucault [10], in the end, it might be the only widely acceptable solution in the largest migration challenge after World War II, which the continent is forced to face. [11]

\subsection{The Challenge of the Researcher}

Who are those that have no permanent home, change 'settings', not because of choice but because of conditions? The stage has been set, the roles are given and the "dis-placed people" [12] become the central characters of the drama being unfolded lately. The specific groups of people being referred here are refugees, requiring asylum, migrants; bare lives that left forcibly from their grounds, due to persecution, chronic conflict or human rights violations. [13]

Today's world talks about a daunting humanitarian crisis or a "refugee's crisis" [14] and architects should attach themselves to this movement, drawing attention to the dangers that lurk like increase of xenophobia and intolerance, creation of ghettos and division of urban areas into deprived and 'healthy' ones. [15]

Based on the above statement, the present paper leads one's 'view' in other visual sights of architecture, in theory and in practice, in which 'many will see, but a few will perceive'. More specifically, this paper in the first-half deals 
with, what we call, 'Bare lives in invisible cities'. Bare lives are defined, as the subjects while invisible cities are the spaces in which they move, temporarily or dwell for a longer period.

It is, therefore, an open epic chapter of the modern unavoidable immigration that will be described, because it constitutes a chapter of current time although it has not received the required attention yet. The mandatory movement of some 'unwelcome' subjects [16] towards the European capitals is a contemporary challenge and have constituted the researcher with a significant challenge in her attempt to identify the housing policy that applies to them in the countries that temporarily host them. Another challenge to the selection of the project/study statement was the importance to identify the architectural issues emerging from the refugees' crisis and introduce ways to avoid them. Therefore, this study does not intend to stage a tearful drama of misery, but seeks to introduce an accommodation centre for asylum-seekers based on a low budget design and the concept of reuse architecture, aiming to discuss a new type of co-habitation in the city.

The researcher is aware that the task to provide architectural solutions for such a sensitive subject is not straightforward. However, there has never been a more appropriate time for design proposals, which correspond, to this problem and a broader debate about the issues raised by the so-called "refugee's crisis." [17] In any case, the practice of designing with an illusion for a purely virtual development by crossing our fingers and without considering the cultural, political, social and religious differences which eventually lead to clashes is out of date.

\section{The Phenomenon of Redundant Humanity [18] and the Reception Centres}

As mentioned above, in the centre of the so-called "bio-political body,"[19] the displaced ones -immigrants, asylum seekers, without-legal-documents - rejected from the world order moving or being transferred from one place to another lie today. These are the excessive or redundant population, who are deprived of adequate means of survival and for whom the planet is fast running out of places to put. [20] It is clear that the countries who ordinarily host these people including Turkey, Pakistan and Middle East, are no longer able to cope and European leaders has so far failed to make substantial decisions on the issue of hosting refugees. [21] Allegorically, it can be said that the current redundancies have been caught in a continuous pass mode, hovering in a spatial vacuum, in which time has stopped; waiting and wondering how to start their lives? In this paper, the question is set to the architect.

Until today, as a respond to this 'uncomfortable' situation, the European Union provides the so-called 'reception centres'. The Italian philosopher Giorgio Agamben and the
Polish sociologist Zygmunt Bauman evaluate these centres and designate them as 'camps' where wasted lives, live' [22], like a prison or a ghetto. One might say that these camps are conceived and designed as a gap in time and space, built in the most remote and isolated parts of the country as possible - these 'permanent/temporary camps' are selected having as main criterion the greatest distance from 'civilized' city centres. [23] Obviously, the main design idea of these centres perpetuates xenophobia and meiktofovi ${ }^{1}$ increasing stereotypes about the grimness of the great unknown. Schematically, it could be said that they define a black and white setting, built away from the world, where our protagonists just survive.

Apparently, the European Union (E.U.) devotes much time and grey matter in the design of increasingly sophisticated ways to set and fortify its borders, and to devise the most appropriate discharge procedures from those who simply seek shelter and food. [24] At last, E.U. restricts its social role, strengthens and expands the criminal intervention choosing a security policy. [25] However one thing is certain; the doors might be closed sharply, but the problem will not disappear. With such superficial strategies the relief tends to be short. The locks may keep the problem away from our sight and thoughts, but surely refugees will keep coming, searching for some hope for themselves and their families due to their lack of real options. [26]

Overall, the redundant humanity is increasingly caught in the crossfire; forced or frightened to leave their countries and simultaneously denied access to many others. They do not only change their place; they lose their place on Earth. As mentioned by Zygmunt Bauman: [27] "They are thrown to nowhere;" to the "non-places" (non-lieux) of Marc Auge, [28] "the cities of nowhere" (nowherevilles) of Joel Garreau and "the ship of fools" (Narrenschiffen) of Michael Foucault. [29] In the current paper, those 'places' raised by Bauman and others, are replaced as terms from the 'Invisible cities.'

\subsection{Subject; Bare lives}

In general, refugees, requiring asylum or migrants are redundant humans and therefore one thing is certain that they now are stateless people.[30] Zygmunt Bauman in his book "Wasted lives" describes them as "the waste products of globalization." [31] Think for a moment that you lose a set of everyday things, and people in which your social existence is based, home, family, work, assets. These people have nothing more than their unprotected and bare life.

The attention falls to the latter as in the current paper the protagonists are introduced as 'bare lives.' Giorgio Agamben [32] introduced the term in order to describe a person without

1 The increasing pluralism and the cultural diversity in the urban environment create the feeling of meiktofovia. The latter is defined as the fear of the irritatingly chaotic and unfamiliar character of the social environment in the city, which intensifies the tensions and the division's trends (Bauman). 
rights. "Bare life is the situation in which a human being turns to a carrier, only carrying its ordinary biological functions rather than rights," he says. In addition, Zygmunt Bauman [33] points out "these others, at the instant they find themselves outside the borders of their homeland, are deprived of the support of any recognized state authority which can take them under its protection, to defend their rights and to protect them against foreign forces." In simple words, the displaced people are isolated from every element of their identity except of this: that of being without place.

Schematically, observing bare lives, they seem like the figures of Giacometti [34] in his sculpture entitled "City square;" uniform figures leave the observer with the impression that they swing, ever seeking for their identity, temporarily shaping their lives and waiting, never losing faith, always hoping in a better future. In this research, they are observed, building their own architecture, 'the architecture of silence' or humble architecture, which is all but silent in contrast with its name as it is considered as unclean, infectious, parasitic and it causes disorder - spatial and visual - in the city. [35]

\subsection{Setting: Invisible Cities}

This research, having defined its subjects, attempts to set them in the invisible cities' grounds. What is the definition of an Invisible city? Where is it located? What kind of new spatial relations are formed? These are some questions require answers.

These non-European migrants or refugees as 'Others' are increasingly encountered in the city and reside anywhere: in deprived neighbourhoods, in outdoor accommodations, in abandoned buildings differentiating city grounds. [36] They transform public space into private and invent intermediate spaces such as sidewalks, overdrafts, urban spaces. [37] Under these conditions, the modern city could be defined as a combination of 'spaces'. These are not identical to one another; therefore the overall image of the city forms a multicultural network creating a variety of images within the city; by the elite enclaves until the enemy ghetto. [38] One might say that a new map appears on the city ground, another 'fabric' woven underground, that of an Invisible city. The term of Invisible city is borrowed by Italo Calvino and herein it refers to the places in the city that are 'removed' from public visibility in urban space by choosing to avoid, to hide or just to ignore them.

Under these new conditions, what is the role of the architect and which alternatives are recommended?

Today, the architect is called upon to weave the thread in the cities between those spaces, 'Other spaces' [39] and yet to devise intermediate areas, which will be the missing link between that 'Other city', (called as invisible city) and the 'real' one. [40] In short, it is of high importance the development of meeting points or temporal communities as spaces of engagement. [41] Based on the above, the researcher intends to create an invisible city through her own perspective. The architectural proposal is briefly described in the following paragraph.

\section{A Setting of a Stopover}

This research (2012-2013), having defined its theoretical framework, attempts to build its proposal design. The resulting design has aimed to give temporary shelter to those who are forced to flee their homes and proposes an organized solution for the people for whom no international status could so far guarantee a safe place. [42,43] So what is presented here is an open accommodation centre for asylum seekers in the city as opposed to the hidden reception centres provided from the E.U as described earlier in this study. Subsequently a detailed description of the proposed design is given focusing on the key design decisions which compose the design proposal.

\subsection{Design Objectives}

The overall aim is to develop architecture of silence, hence the introduction of a humble architecture from this project. The experiment proposes a new form of cohabitation, as a reception area or a meeting place thus it is developed in a Mediterranean city [44] and most of all near of public services, schools, public markets, public transports and more. Specifically, the proposal is located in the old town of Limassol, in Cyprus with moderate urban density and low-height surroundings and is shaped by the desire to create a sense of community that reflects and enhances the setting hosting it. Below the key design requirements, are presented:

- $\quad$ Economy: Given the general negative sentiment for this people, creating a proposal with a significantly low budget, adds to the challenges the designer has to face. In this context, a wise choice for the form of the accommodation unit as well as choice of materials, can offer an interesting prospect in order to make the proposal more realistic.

- Standardization of the form - not repetition: The project must provide simplicity in the form for ease of construction and at the same time avoid a tedious repetition.

- Diversity: An important objective is to create a proposal with a distinctive appearance. The architect wants to exploit available old things and new ones to create a fresh place while keeping a low profile.

- Reuse of materials and restarting people's lives: The proposed scenario requires a new habitat place for newcomers from a variety of many different cultures. On this basis old things will be arranged in a new way while as time goes by, and people here will lay the foundation for their new life. 

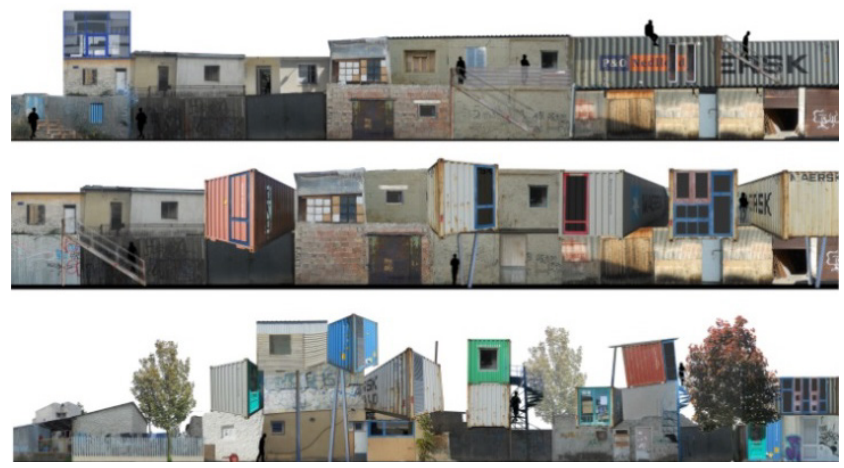

Figure 1. A real gravure: a surreal backdrop

Based on the concept of reuse architecture, the above key design requirements and the ideas introduced by the Spanish artist Dionusio Gonzalez [45] in his project "Favela series, Sao Paolo Brazil (2004-07)," the designer composed a surreal backdrop using the surroundings of the selected area (see Figure 1). The result is an interesting combination with realistic and surreal architectural elements, which the designer used as the starting point for the following architectural proposal.

\subsection{Design Brief}

The architectural concept is based on a minimum functional unit, a slightly modified container (40ft HG), which will act as the basic element of our proposal, as it could respond to the key design requirements. For example, the simplicity of its form with dimensions $12 \mathrm{~m} \times 2.35 \mathrm{mx} 2.70 \mathrm{~m}$ contributes to the ease of construction while makes it suitable to accommodate 2-4 people each.
Both its abundance and sometimes its uselessness in every harbour contribute to its low cost and certainly to the idea of reuse of materials. Its portability and the plenty of options to modify it with promising aesthetic results are more reasons which justify the specific choice.

The design proposal is developed around an internal open space (courtyard) that is of common use. Common functions and facilities (feeding, health care and legal support, leisure, etc.) are located on the ground floor (open and closed spaces), creating a public or/and semi-public space that will ideally operate as a centre of daily life. This becomes also an action-meeting place for guests and locals where actions such as contemporary artistic practices, film projections and more take place. The accommodation facilities are located on the upper floors in order to achieve privacy.

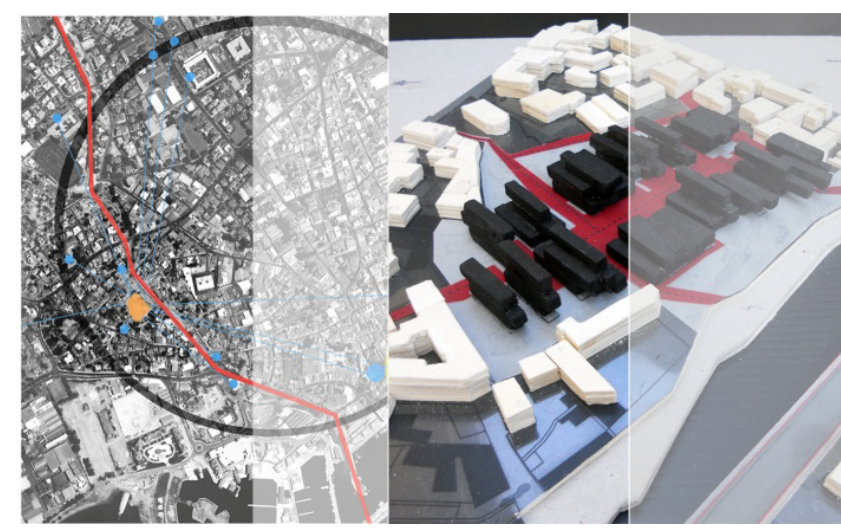

Figure 2. An accommodation centre in the city (physical model 1:500)

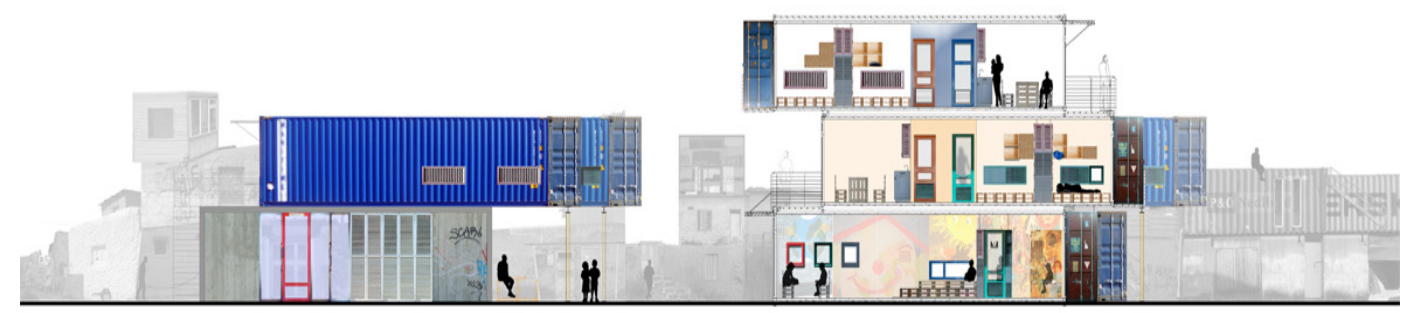

Figure 3. The setting of a Stopover: Economy - Standardization of the form - Diversity - Reuse of materials and Restarting people's lives

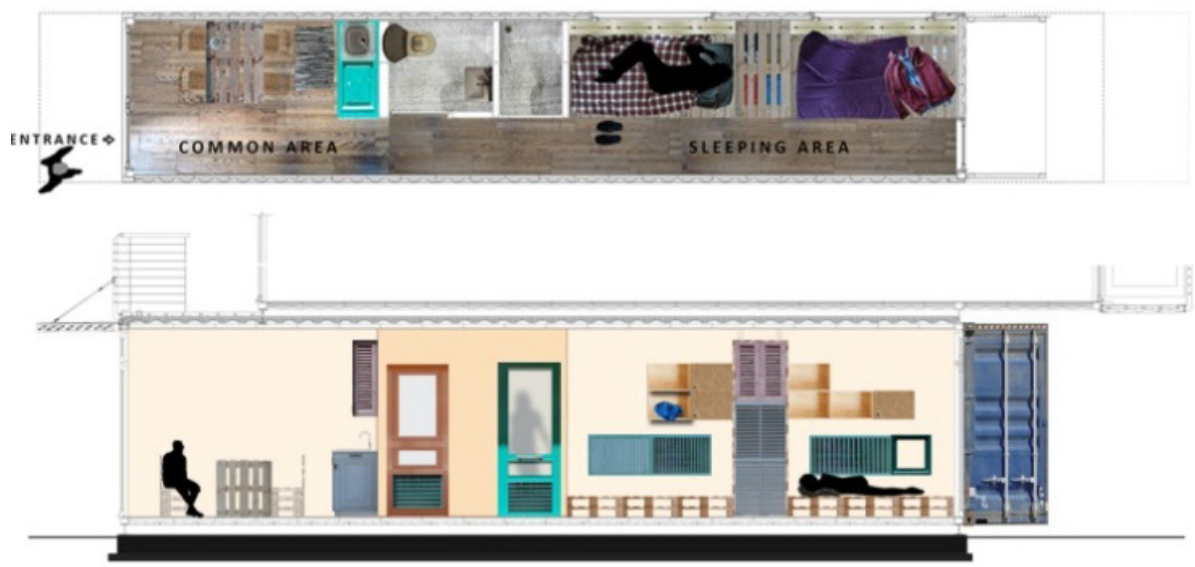

Figure 4. Re-use Architecture; Plan (Top) and Section (Bottom) of the unit 
Special attention is given to the materials, as the fundamental design decision. A brief analysis and an explanation for the selection of the particular materials are given in the following paragraph.

\subsection{Materials}

The crucial aspect of the design concept was to create a modest eco-friendly construction and at the same time to embrace the project with a sense of modernity. Following these thoughts, the proposal was developed on a recently widespread architectural approach, the so-called 'Re-use Architecture.' The setting is therefore built by using any kind of old furniture such as tables, chairs, windows, doors as well as pallets and crates.

In practice, the side views of the container - representing the ground floor - give way to bricklayers, cast concrete and glass while for the other levels old door frames and windows are used to set the scene, by giving the facades a rhythmic diversity. In the same concept, the interior is composed of a set of pallets and crates, which form all the furniture - kitchen, beds, and wardrobe.

It is in a fact that such an architectural approach attracts architects and owners all around the world as it introduces a remarkable architectural vocabulary. Today there are many architectural examples of such solutions. Apart from the work of Shigeru Ban who first introduces such ideas include but not limited to the Paper Emergency Shelter for UNHCR (1999) or the Container Temporary Housing (2011) [46], the Vegan House by Block Architects could be a similar approach (2014). [47] In any case, this type of architecture offers promising prospects in order to start a substantial discussion about the 'unsolved' problem of immigration and the need to be housed.

\section{Conclusions and Recommendations for Further Research}

Given the current policy and feelings towards immigrants, one might say that such an intervention in the city may seem a utopia. Being aware of a utopian approach and having in mind the extreme conditions of these people, emphasis has given to a realistic scenario and an easily achievable design.

However a question keeps rising. Can one change the status quo, referred to our refusal to accept a foreigner with strange habits and other religions in our neighbourhood? Obviously, the subject of migration is vast and within an open-ended discussion; is much more complicated than theory or any design; it is real life. Vasilis Ladas in one of his literary documents, very aptly points out: "Take water with you, the future is expected to have mega drought," [48] as architectural practice has a difficult task in its attempt to find the right balance between meiktofovia and coexistence with the 'Others'.
There is a discussion rising lately in Greece and Europe that refugees might be spread in several multi-storey residential buildings (there is a stock of empty apartments) in several cities. [49] Although this idea sounds as offering independence and faraway of the picture of a ghetto, it raises problems similar to those they claim that will be avoided. Those policies perpetuate isolation, block the smooth integration of refugees in a totally foreign environment and certainly they are costly since they require extra support from social services and more. [50]

Based on all the above, it is obvious that a standard solution does not exist. Each invisible city should be unique, reflective of the style of surrounding properties, sympathetic to the place hosing it and adapted to the community spirit. There are directions, as well as opportunities to get out of the 'mess', that cannot be always found in sophisticated designs, but could perhaps be discovered among creative, economic and simple actions. [51]

One thing is clear. Architecture should not only be a medium for momentary impressions. Architecture is a tool to improve lives and it is now more widely understood that architectural practice should encourage such a social development. Refugees, asylum-seekers or immigrants, the today's 'damned', deserve our attention and to a certain point our solidarity as there are universal values in the world, which of the protection of life comes first. The words of Italo Calvino in "Invisible Cities" are absolutely representative as it is time to "seek and learn to recognize who and what, in the midst of inferno, are not inferno, then make them endure, give them space."[52]

\section{Acknowledgements}

I would like to express my sincerest thanks to my supervisor Dr. Fani Vavili, for her useful comments, immense knowledge and her support throughout this thesis. Her advice was crucial and very useful in order to fulfil this project. Special thanks to A.P. for his invaluable support.

\section{REFERENCES}

[1] Z. Bauman. Wasted lives: Modernity and Its Outcasts, trans. Marcos Karasarinis, Katarti, Athens, 2005.

[2] M. Foucault. Introduction, In Madness and Civilization: A History of Insanity in the Age of Reason, trans. Richard Howard, New American Library, 1971.

[3] I. Calvino. Invisible Cities, trans. Anteos Xrisostomidis, Kastaniotis, Athens, 2004.

[4] C. Purvis. Europe's Refugee Crisis, International Rescue Committee (IRC), September, 2015, Online available: http://www.rescue.org/sites/default/files/resource-file/IRC\%2 0-\%20Europe's\%20Refugee $\% 20$ Crisis $\% 20$ Policy $\% 20$ Brief $\%$ 


\section{0-\%20September\%202015.pdf.}

[5] International Rescue Committee (IRC). Europe marks 1 million refugees, December 22, 2015, Online available: http://www.rescue.org/blog/europe-marks-1-million-refugees.

[6] International Organization of Migration (IOM). Fatal Journeys: Tracking Lives Lost during Migration, 2014, Available: http://reliefweb.int/sites/reliefweb.int/files/resources/Fatal-Jo urneys-Tracking-Lives-Lost-during-Migration-2014.pdf

[7] Specifically, the term of Invisible city is borrowed by Italo Calvino and it refers to the places in the city that we choose to avoid, to hide or just to ignore. Calvino, Invisible Cities.

[8] E.Tzirtzilaki. Dis-placed, Urban nomads in the Metropolis: Contemporary Issues Concerning Movement, the City and Space, Nissos Academic Publishing 8, Athens, 2009, pp. 243.

[9] ibid.

[10] M. Foucault. Stultifera Navis, In Madness and Civilization: A History of Insanity in the Age of Reason, trans. Paris Mpourlakis, Kalentis, Athens, 2007.

[11] International Rescue Committee (IRC). Refugee Crisis, Online available: http://www.rescue.org/refugee-crisis.

[12] Tzirtzilaki, Dis-placed, Urban nomads in the Metropolis.

[13] UNHCR, Sea Route.

[14] Purvis, Europe's Refugee Crisis, 5.

[15] Tzirtzilaki, Dis-placed, Urban nomads in the Metropolis.

[16] UNHCR. The sea route to Europe: The Mediterranean passage in the age of refugees, 2015, pp.18, Online available:http://www.unhcr.org/cgi-bin/texis/vtx/home/opend ocPDFViewer.html?docid $=5592 \mathrm{bd} 059$ \&query $=$ refugees $\% 20 \mathrm{c}$ risis\%20Europe

[17] Purvis, Europe's Refugee Crisis, 5.

[18] Bauman, Wasted lives.

[19] Tzirtzilaki, Dis-placed, Urban nomads in the Metropolis, 243.

[20] Z.Bauman. Liquid Love: On the Frailty of Human Bonds, trans. George Karampelas, Hestia, Athens, 2007.

[21] Purvis, Europe's Refugee Crisis, 10

[22] G.Agamben. Form of Life, Eleutheriaki Koultoura, Athens, 2002 , pp. 42

[23] Bauman, Liquid Love, 209.

[24] Z. Bauman. Humanity in motion, In Liquid Times: Living in an Age of Uncertainty, trans. Konstantinos Geormas, Metaixmio, Athens, 2009.

[25] International Rescue Committee (IRC). Refugee crisis: The IRC's recommendations for Europe, September 10, 2015 , Online available:

$\mathrm{http} / /$ www.rescue.org/blog/europe-refugee-crisis-irc-policy-r ecommendations.

[26] Migration Policy Institute. Before the Boat: Understanding the Migrant Journey, May 2015, Online available: http://www.migrationpolicy.org/ research/boat-understanding-migrant-journey
[27] Bauman, Liquid Times, 82.

[28] M. Auge. Non-places: an introduction to an anthropology of super modernity, trans. John Howe Verso, London, 1995.

[29] M.Foucault. Of Other Spaces, Heterotopias. In Architecture, Mouvement, Continuité, 1984.

[30] V.Ladas. Mousaferat: One thousand and one nights of a refugee camp, futura, Athens, 2008, pp. 30.

[31] Bauman, Wasted lives.

[32] Agamben, Form of Life, 41.

[33] Bauman, Liquid Times, 67.

[34] A.Giacometti, A.Schneider, L.Grisebach, E.Clegg. Alberto Giacometti: sculpture, paintings, drawings, In Scale in Giacometti's Sculpture, Prestel, London, 2008.

[35] Ladas, Mousaferat.

[36] E.Fotiadi. Flesh, stone and contemporary artistic practices, Nomadic architecture network, November 17, 2015, Online available:

http://nomadikiarxitektoniki.net/en/texts-en/flesh-stone-and-c ontemporary-artistic-practices/\#more-1056

[37] Tzirtzilaki, Dis-placed, Urban nomads in the Metropolis, 246.

[38] ibid.

[39] Foucault, Other Spaces, 46-49.

[40] Initiatives and actions by the Nomadic Architecture network come to mind here. Nomadic Architecture Network. Available: nomadikiarxitektoniki.net.

[41] Nomadic architecture network. "Meeting," Online available: http://nomadikiarxitektoniki.net/en/category/projects/utopiameeting

[42] H.Arendt. The Origins of Totalitarianism. Milano, 1996.

[43] UNHCR, Sea Route.

[44] Most refugees arriving on the Mediterranean shores (Italy or Greece). Purvis, Europe's Refugee Crisis, 8.

[45] "Favelas Series," Dionusio Gonzalez, Online available: http://www.dionisiogonzalez.es/.

[46] AD Editorial Team. The Humanitarian Works of Shigeru Ban, ArchDaily, March 24, 2014, Online available: http://www.archdaily.com/489255/the-humanitarian-works-of -shigeru-ban.

[47] Vegan House/Block Architects, ArchDaily, June 14, 2015, Online available:

http://www.archdaily.com/641621/vegan-house-block-archite cts.

[48] Ladas, Mousaferat, 30.

[49] Fani Vavili, interview by Elina Triantafyllidou, November 15, 2015.

[50] ibid.

[51] Available: nomadikiarxitektoniki.net.

[52] Calvino, Invisible Cities, 198. 